\title{
Update on Surgical Management of Small Bowel Neuroendocrine Tumors
}

\author{
DEMETRIOS MORIS ${ }^{1}$, IOANNIS NTANASIS-STATHOPOULOS ${ }^{2}$, DIAMANTIS I. TSILIMIGRAS ${ }^{2}$, \\ STYLIANOS VAGIOS ${ }^{2}$, ANDREAS KARAMITROS ${ }^{2}$, GEORGIOS KARAOLANIS ${ }^{2}$, JOHN GRINIATSOS ${ }^{2}$, \\ ALEXANDROS PAPALAMPROS ${ }^{2}$, IOANNIS PAPACONSTANTINOU ${ }^{3}$, GEORGIOS K. GLANTZOUNIS ${ }^{4}$, \\ ELEFTHERIOS SPARTALIS ${ }^{2}$, DAN G. BLAZER $3 \mathrm{rd}^{1}$ and EVANGELOS FELEKOURAS ${ }^{2}$ \\ ${ }^{1}$ Department of Surgery, Duke University Medical Center, Duke University, Durham, NC, U.S.A.; \\ ${ }^{2}$ First Department of Surgery, National and Kapodistrian University of Athens, \\ Medical School, Laiko Hospital, Athens, Greece; \\ ${ }^{3}$ Second Department of Surgery, National and Kapodistrian University of Athens, \\ Aretaieio University Hospital, Athens, Greece; \\ ${ }^{4}$ Department of Surgery, Ioannina University Hospital, Ioannina, Greece
}

\begin{abstract}
The widespread use of endoscopy and imaging in combination with the continuous update of the staging systems for neuroendocrine tumors has led to an increase in the incidence of small intestinal neuroendocrine tumors (siNENs) globally. Despite high survival rates, severe complications may occur even in early stages due to the anatomic location of the primary site and the desmoplastic reaction. Surgery plays a central role in the management of patients with si-NENs. Excision of locoregional disease along with extensive lymph node dissection should be performed in fit patients, even in the presence of metastases. Multimodality treatment of liver metastases includes hepatectomy, ablative techniques and liver transplantation. Hormone therapy with somatostatine analogs is of high importance for symptomatic control; special caution should be exercised both pre-and intra-operatively. A multidisciplinary approach is essential in order to provide personalized therapeutics for patients with si-NENs. Clinical research and specialization in this field should be further encouraged.
\end{abstract}

This article is freely accessible online.

Correspondence to: Demetrios Moris, MD, MSc, Ph.D., MACS, Department of Surgery, Duke University Medical Center, Duke University, 2310 Erwin Rd, Durham, NC 27710, U.S.A. E-mail: dimitrios.moris@duke.edu

Key Words: Neuroendocrine tumors, small intestine, jejunum, ileum, cancer, review.
Small intestinal neuroendocrine tumors (si-NENs) are the most common neoplasms of the small intestine and are mainly found in the terminal ileum (1). They are usually focal lesions, less than $2 \mathrm{~cm}$ in diameter; however, one-third of cases present with multifocal disease (2). Their incidence has increased from $1.09 / 100,000$ person-years in 1973 to $5.25 / 100,000$ personyears in 2004 (3). This is mainly attributed to medical advances in recent decades, including staging systems, endoscopic examinations, improvement of imaging modalities and pathological examinations of surgical specimens. A diagnostic algorithm for si-NENs is depicted in Figure 1. The current classification of si-NENs is described in Table I.

In a large series of patients with gastroenteropancreatic NENs diagnosed between 1973 and 1997, 44.7\% were siNENs, among which more than $50 \%$ were located in the ileum $(1,3)$. Median age at diagnosis is 66 years and $52 \%$ of the patients are males (4). In a recent meta-analysis, ever smoking, and family history of malignancy or colorectal cancer were significantly associated with increased risk of si-NEN (5).

Most patients with si-NENs have prolonged survival due to the low NEN cell proliferative rate and, thus, patients with localized disease have a 5-year overall survival (OS) rate of 70$100 \%$, whereas for those with distant metastases, more common in the liver, it is $35-60 \%$ (6). In autopsy studies, the reported incidence of si-NENs is high $(8,34 / 100,000)$, indicating that their true incidence may be higher than suspected, since many will remain undiagnosed due to lack of clinical manifestations (7).

The mainstay of si-NEN therapeutics is surgery, which may be curative in the case of R0 resection (8). However, in most patients, R0 resection is far from feasible mainly due to advanced stage at diagnosis. In this setting, surgery aims to 


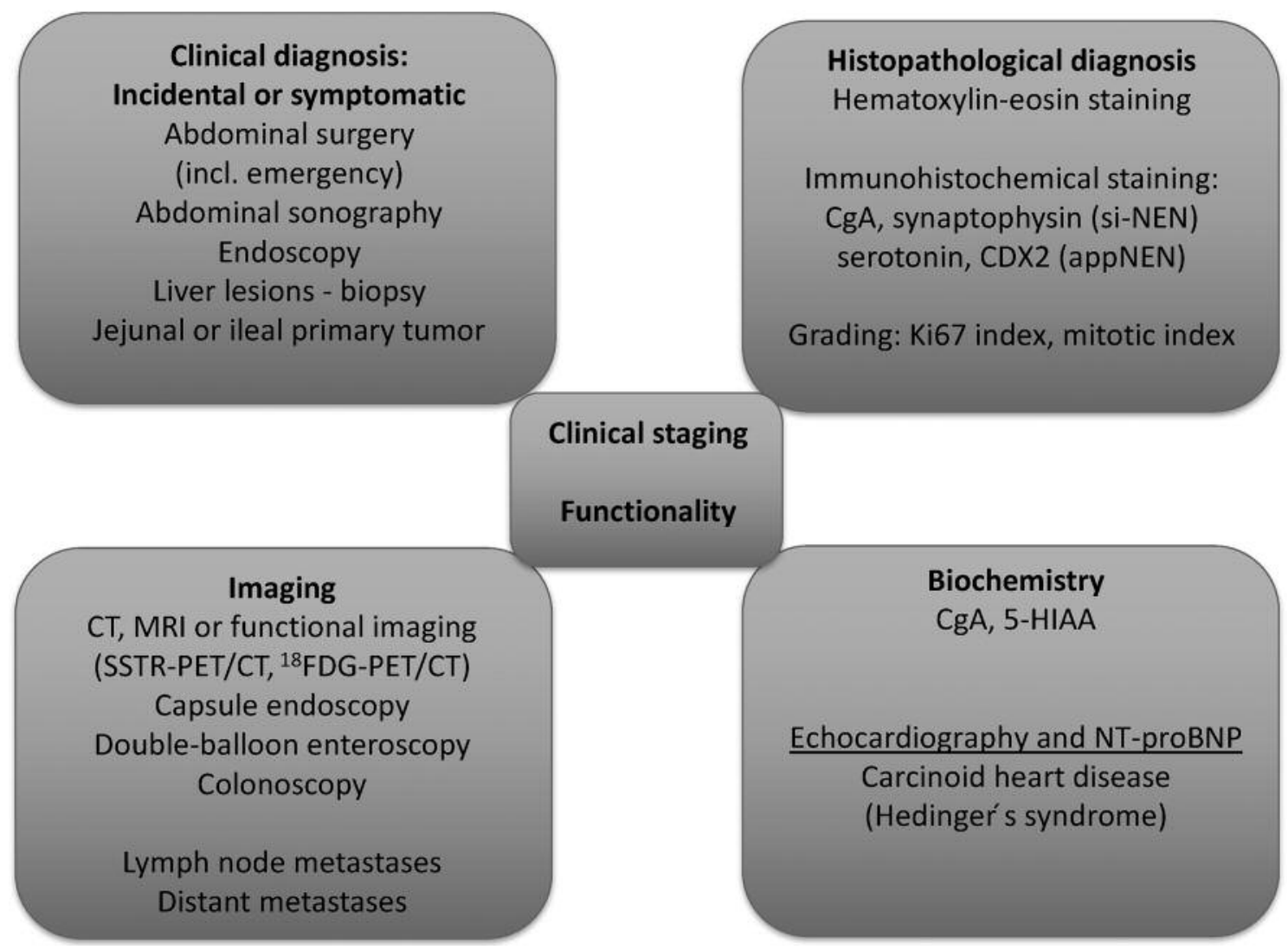

Figure 1. Diagnostic algorithm for small intestinal neuroendocrine tumors. CgA: Chromogranin A; appNEN: neuroendocine tumor of the appendix; 5-HIAA: 5-hydroxyindoleacetic acid; CT: computed tomography; MRI: magnetic resonance imaging; SSTR: somatostatin receptor; PET: positronemission tomography; ${ }^{18} \mathrm{FDG}:{ }^{18} \mathrm{~F}$-deoxyglucose; NT-proBNP: N-terminal pro B-type natriuretic peptide.

reduce the disease burden in order to improve survival. Patients with operable disease have better prognosis than those with inoperable, even in advanced stages $(9,10)$. Approximately $80 \%$ of disease-related deaths are due to liver insufficiency and $16 \%$ due to bowel obstruction; therefore, surgical intervention may help improve survival and quality of life (11).

Surgical management is challenging, also taking into consideration that approximately $30 \%$ of cases present with multifocal disease and more than $50 \%$ (up to $80 \%$ ) present with metastatic disease at diagnosis (12). For inoperable cases, hormone symptom control and suspension of tumor proliferation should be among the therapeutic aims.

Herein, we review the current knowledge in the surgical management of si-NENs. The principles of surgical treatment are summarized in Table II.

\section{Preoperative Care}

Preoperative tests should include computed tomography (CT) or MRI, somatostatin receptor scintigraphy (SRS) or ${ }^{68}$ gallium positron-emission tomography (PET)/CT, 5-hydroxyindo- leacetic acid (5-HIAA) levels in 24-h urine sample, and echocardiogram for assessing the burden due to carcinoid syndrome (10). The main scope of this workup is the prevention of perioperative carcinoid crisis presenting with hyperthermia, shock, arrhythmias, hyper- or hypotension, tachy- or bradycardia, flushing or bronchospasm.

Upon evidence or suspicion of carcinoid syndrome, therapy with somatostatin analogs (SSA), such as octreotide, should start at least 1 day before surgery, continue during the surgical procedures and up to at least 1 day postoperatively; caution should be exercised in the gradual discontinuation (13). This approach applies even for minor surgeries (14). Risk magnitude and the severity of a crisis are difficult to forsee; however, patients with a known uncontrolled syndrome are at a very high risk. There is also a high risk in cases of large tumors that secrete serotonin such as during liver metastasectomy or liver transplantation (14). Prevention remains the best therapeutic strategy in this setting.

Before surgery, any electrolytic disturbances should have been corrected. Preventive administration of octreotide is usually enough for minor surgeries (15). For major surgeries, 
Table I. TNM staging system according to the American Joint Committee on Cancer 8th edition, 2017 (23).

\begin{tabular}{lccc}
\hline Tumor* & Nodal status & Metastasis & Stage \\
\hline T1 & N0 & M0 & I \\
T2 or T3 & N0 & M0 & II \\
T4 & N0 & M0 & III \\
Any T & N1, N2 & M0 & III \\
Any T & Any N & M1 & IV \\
\hline
\end{tabular}

*For multicentric disease, the highest $\mathrm{T}$ category should be taken into consideration. T1: Lamina propria or submucosal invasion and $\leq 1 \mathrm{~cm}$; T2: muscularis propria invasion or $>1 \mathrm{~cm}$; T3: subserosal tissue invasion without penetration of overlying serosa; T4: invasion of visceral peritoneum or other organs or adjacent structures. N1: Regional lymph node metastases in $<12$ nodes; N2: large mesenteric masses $>2 \mathrm{~cm}$ and/or extensive nodal deposits $>12$ nodes especially those encasing superior mesenteric vessels. M1: distant metastasis.

a preoperative dose of octreotide is followed by a continuous infusion during surgery that should be doubled in the case of carcinoid crisis. Postoperative discontinuation is gradual, with $50 \%$ reduction each day (14).

Other supportive care is administered as indicated. Intraoperative hypotension not attributable to blood loss, and bronchospasm necessitate the administration of fluid, octreotide and steroids, whereas the use of vasoconstrictors is debatable since they may reinforce serotonin and amine secretion (14).

\section{Locoregional Enterectomy with Lymph Node Dissection}

Surgical resection of the primary tumor with locoregional mesenteric lymph node dissection and metastasectomy, if feasible, is the only curative approach (16), although R0 resections have been reported to be feasible in only $20 \%$ of cases (17); however, it has been reported that the current rate is even higher (18).

Surgical intervention depends on the primary tumor site: oncological right hemicolectomy for tumors of the terminal ileus, small bowel enterectomies for more proximal si-NENs. Although fewer than $40 \%$ of tumors are multifocal, intraoperative inspection and palpation of the whole small bowel is considered of utmost importance (19).

Mesenteric lymph node metastases are usually present and aggravate the prognosis. Systemic lymph node dissection along with enterectomy may improve survival and rate of complications (20). Optimal lymphadenectomy may be really challenging, especially when there is coexistence of mesenteric fibrosis or large lymph node metastases of the superior mesenteric artery (SMA) (21). Optimal enterectomy with optimal lymphadenectomy is vital for improving survival and preventing recurrence $(6,20,22)$. Therefore, it is advisable that such operations be conducted at specialized centers with relevant expertise treating a large number of patients.

Even in the presence of metastatic disease, patients with siNEN should undergo optimal surgery with lymphadenectomy in order to prevent ischemia, obstruction, and perforation. Dissection of at least eight $(10,14,20)$ or 12 (23) lymph nodes has a positive impact on survival. A recent metaanalysis showed that among patients with metastatic disease, palliative resection of the primary tumor conferred a survival benefit (24).

In the presence of liver metastases, locoregional disease control gives the opportunity to focus on the treatment of hepatic disease, whereas it improves symptoms and, thus, quality of life $(6,25)$.

Lymph node skip metastases have been reported and systematic and extended lymph node dissection in the retropancreatic area may be necessary in order to prevent logoregional recurrence (26).

\section{Surgical Procedure}

Intraoperative exploration with a radioguided detector has shown promising results in guiding resection of the primary tumor and metastatic lymph nodes. However, technique standardization and specific guidelines for its role are still under debate (27). Whole small bowel (from Treitz ligand to the ileocecal valve) inspection and palpation with both hands is of great importance for pinpointing otherwise undetectable tumors $(10,18)$. Preoperative CT- or MRI- angiography may be useful in determining the tumor and the lymph nodes sites in relation to the vessels, so that the optimal surgical resection is feasible, with adequate length of small bowel left behind (at least three jejunal arteries) in order to prevent short bowel syndrome $(28,29)$. Residual metastatic lymph node disease may result in mesenteric ischemia or recurrent obstructive episodes, therefore a thorough investigation and dissection of malignant lymph nodes is important (14). Concurrent cholecystectomy is also preferable because the adjuvant treatment with SSAs and, possibly, chemoembolization may cause cholestasis, with a high risk of complications such as necrotic cholecystitis $(18,29)$.

The ileocecal valve should be preserved, if it is oncologically acceptable, especially in patients with carcinoid syndrome in whom the lack of ileoceccal valve reduces the postoperative quality of life. It is estimated that up to $40 \%$ of cases may retain the ileocecal valve (14). Boudreaux et al. conducted several studies assessing the role of stains such as isosulfan blue or methylene blue in the mapping of lymphatic drainage $(9,14,30)$. If the lymphatic vessels of the ileocecal valve are colored, then there is a high risk of metastasis and right hemicolectomy should be 
Table II. Principles of surgical treatment.

General Principles

1. Primary tumours are small and may present with numerous and bulky metastases

2. Locoregional mesenteric lymph nodes, liver and peritoneum are the most common site of metastasis

3. Metastases in the mesenteric lymph nodes may cause desmoplastic reaction, fibrosis and serious complication leading to morbidity and mortality Thus, enterectomy with lymphadenectomy provide a survival benefit and they should be performed in these patients (18)

4. Primary tumor resection may improve survival even in the presence of unresectable liver metastases

5. Regarding resection of liver metastases, enucleation or parenchymal-sparing hepatectomy or other non-R0 resections are acceptable, since they may improve survival

6. RFA, usually in combination with surgery, is very important for treating these patients

7. Extrahepatic disease is not always a contradiction for surgery

8. A specialized center with highly expert surgeons and a multidisciplinary team is vital for the personalized treatment of patients with si-NEN and confers a survival benefit

Stage I-III (curative surgery)

1. Patients with stage I-III si-NENs should undergo curative resection with lymphadenectomy across mesenteric vessels with respect to vasculature of the residual bowel $(88,89)$

2. 5- And 10 -year OS is $100 \%$ for stages I and II, and $>95 \%$ and $80 \%$, respectively, for stage III $(20,90)$

3. For tumours located in terminal ileum, a right hemicolectomy may be necessary (88)

4. Mapping of lymphatic vessels may help in determining the optimal extend of surgery, but the method remains to be standardized (91)

5. In cases of intense desmoplastic reaction around SMA, radical excision of tumour may be impossible.

6. Up to $20 \%$ of the patients may present with multicentric disease detected by CT, MRI, SRS or intraoperative palpation. However, it does not change the indications for surgerical intervention (88)

7. Symptomatic and preoperative carcinoid syndrome control is feasible with SSA administration

8. Currently, there are insufficient data regarding the role of laparoscopic surgery in si-NENs (88)

9. Prognosis may be poor in advanced stages with extrahepatic metastases, such as in peritoneal carcinomatossi or "frozen abdomen or pelvis"

10. Age, disease stage and complete resection are indepedent prognostic factors of survival (88)

11. Postoperative supportive care with drugs such as cholestyramine or dietary support may be necessary

12. Postoperative mortality and morbidity should be less than $2 \%$ and $20 \%$, respectively

13. Neoadjuvant and adjuvant treatment do not seem to have any benefit among patients eligible for curative surgical intervention

Stage IV (palliative surgery)

1. In cases of stable disease with limited hepatic metastasis, surgical resection with curative intent is the treatment of choice (48). Complete R0 resection is associated with 5-year OS and PFS at 70.5\% and 29\%, respectively, in retrospective studies. However, metastatic liver disease has a high recurrence rate of $70-94 \%$ at 5 years

2. Palliative surgery aims to improve survival and render liver metastases as the sole therapeutic issue

3. In cases of distant metastasis, the option of primary tumor resection depends on three factors:

a) If curative resection of liver metastases is feasible (70), then oncological surgery of the primary tumour should be also performed

b) In symptomatic patients due to complications from the primary tumor site, palliative resection of the primary tumor and radical resection of mesenteric lymph node metastases should be performed

c) Various factors including the patient's performance status and the anticipated benefit from each surgical intervention should be taken into consideration (87). Treatment should be individualised

4. Locoregional treatment modalities should be considered as second-line treatment option for patients with mainly liver metastases and may improve survival (70). Systematic treatment should be administered in progressive disease with extrahepatic lesions (44)

5. TAE and TACE do not statistically significantly differ in terms of outcomes (54)

6. SIRT (DEB-TACE) is a promising method but possible complications such as bilomas and abcesses should be considered. SIRT may be complementary to PRRT. Compared to TACE, SIRT may be implemented in patients with bilateral disease (44)

RFA: Radiofrequency ablation; si-NEN: small intestinal neuroendocrine tumors; OS: overall survival; SMA: superior mesenteric artery; CT: computed tomography, MRI: magnetic resonance imaging; SRS: somatostatin receptor scintigraphy; SSA: somatostatin analogs PFS: progressionfree survival; TAE: transarterial embolization; TACE: transarterial chemoembolization; SIRT: selective internal radiation therapy; DEB-TACE: drugeluting bead TACE PRRT: peptide receptor radionuclide therapy.

performed. This is usually the case in those with tumors exceeding $1 \mathrm{~cm}$ and in the presence of bulky mesenteric lymph nodes (14). Otherwise, the preservation of the ileocecal valve is suggested. Lymphatic mapping may also provide useful data regarding the link between a primary tumor and multiple primary small bowel tumors (30). This may provide a basis for the monoclonal origin of synchronous si-NENs by serial lymphatic interstitial spread 
caused by the obstruction of the central lymphatic drainage at the mesentery root due to the tumor and desmoplastic fibrosis (30). The same rationale may be applicable for explaining local recurrence. In this context, Boudreaux et al. (14) have proposed colored lymphatic vessels as delineating a new resection margin, instead of the rather arbitrary $5 \mathrm{~cm}$. Such an approach has resulted in the improvement of survival, with 5- and 10-year OS reaching $87 \%$ and $77 \%$, respectively, compared to $54 \%$ and $30 \%$, respectively (9). However, this method extends the resection of small bowel to $7-10 \mathrm{~cm}$, which may have aggravated diarrhea postoperatively. Preservation of the ileocecal valve may be beneficial in this setting (31).

\section{Mesenteric Lymph Node Metastases and Desmoplastic Fibrosis}

Si-NENs tend to metastasize to the lymph nodes of the mesentery root and present with bulky disease. These lymph node masses may enlarge and secrete hormones and result in desmoplastic reaction and peritoneal fibrosis. Consequently, mesenteric vessels may be encapsulated and develop thrombosis; cisterna chyli, pancreas and duodenum may also be encapsulated, with subsequent abdominal pain after meals and possibly duodenal or small bowel obstruction. This clinical presentation may result in abstinence from food, weight loss and malnutrition. SMA encapsulation result in collaterals that predispose for lower gastrointestinal hemorrhage and may provoke small bowel ischemia or even necrosis. Cisterna chyli rupture is possible and may result in bile ascites that necessitates surgical intervention. Furthermore, desmoplastic reaction may result in retroperitoneal fibrosis, ureteral obstruction and hydronephrosis (32).

In this context, resection of mesenteric lymph nodes is considered vital. A study has classified lymph node metastases into four stages in order to facilitate the preoperative surgery plan. Only stage IV metastases were considered inoperable, due to the fact that optimal lymphadenectomy would be dangerous in terms of vascularization of the remaining bowel (28).

In cases of SMA stenosis or thrombosis, transjugular intrahepatic portosystemic shunt at the level of the mass is a viable option (33). This approach was associated with obstruction resolution in $93 \%$ of cases and enteric ischemia improvement in $83 \%$ (34).

Conclusively, approximately $80-88 \%$ of patients with siNENs present with lymph node metastases at diagnosis (6, 22). Systematic lymphadenectomy with dissection of at least eight lymph nodes is important and confers a survival benefit (10). Some authors suggest $12 \mathrm{lymph}$ nodes as the cut-off value (28), still others believe that disease recurrence is not predominantly influenced by lymphatic spread but by other factors such as multifocal disease, which should also be taken into consideration (22). Optimal lymphadenectomy has not yet been standardized and is rather debatable (10). Lymphadenectomy is not associated with the length of surgical specimen (28). Furthermore, the 'pizza pie' approach should be abandoned and the inverse approach should become standard (28). Lymphadenectomy should precede enterectomy with possible ileoceccal valve preservation $(10,18,28,35)$. R0 resection of both primary tumor and lymph node metastases is feasible in $80 \%$ of cases $(10,18,19,36)$. Only in a minority of patients with bulky mesenteric masses is optimal debulking not feasible (36). However, surgical intervention may alleviate symptoms (36).

Regarding a laparoscopic approach, it may be considered only in cases with preoperative evidence of localized disease and absence of tumor masses (37). Laparotomy is the standard of care since it enables the exploration of the peritoneal cavity and mesenteric vessels, as well as the palpation of the small bowel $(17,18)$.

\section{Liver Metastases}

si-NENs are most frequently metastatic at diagnosis compared to other gastrointestinal NENs (38-40). Excluding lymph nodes, the liver is the primary site of metastatic disease; up to one half of patients with primary tumor exceeding $2 \mathrm{~cm}$ present with hepatic metastases.

Liver resection. There are multiple approaches in the therapeutics of liver metastases including hepatectomy, thermal destruction [radiofrequency ablation (RFA), microwave ablation (MWA)], arterial embolism (TAE), chemoembolism (TACE), selective internal radiation therapy (SIRT), targeted therapy [peptide receptor radionuclide therapy (PRRT)] and liver transplantation. In patients with grade $1 / 2$ si-NENs, hepatectomy is the standard of care in fit patients; however, its role is debatable in those with grade 3 tumors (41). Following surgery, 5-year OS is 60-80\%. Multidisciplinary consensus meetings are deemed necessary in order to formulate a personalized treatment approach for each patient (16).

According to current European Neuroendocrine Tumor Society guidelines (42), resection of liver metastases should be considered when $\mathrm{R} 0$ resection of grade $1 / 2$ metastatic tumor is feasible with acceptable predicted morbidity $(\sim 30 \%)$ and mortality $<5 \%$, in the absence of right heart failure or extra-abdominal metastases and diffuse peritoneal carcinomatosis; however, the latter is debatable in terms of cytoreductive surgery $(9,16,43)$.

The type of liver resection (metastasectomy, partial hepatectomy, liver transplantation) depends on various factors including tumor biology, number, size and site of lesions, performance status, and predicted remaining liver function (44). Denucleation or parenchymal-sparing 
hepatectomy is currently the most preferable approach for many surgeons $(45,46)$. Combining surgery and RFA or MWA may be a feasible approach for preserving postoperative liver function. It has been supported that $>70 \%$ or even $90 \%$ of the metastatic burden in liver should be resected for obtaining clinical benefit (36). Recent studies have shown that debulking surgery with a cut-off at $70 \%$ has resulted in 5 -year OS of $75 \%(9,36)$. Thus, it may be a feasible option in patients with advanced-staged disease.

In contrast to liver metastases from other types of cancer, surgical intervention in metastatic liver disease from NENs does not necessitate an R0 resection, although this would be the optimal approach $(46,47)$. The rationale behind this approach is that these types of metastases are not invasive, meaning that denucleation is an acceptable approach when $\mathrm{R} 0$ resection is not possible. Indeed, major cytoreductive surgery has shown similar outcomes with R0 resections (11).

Retrospective studies between 1990 and 2001 included a small number of patients (median $=19$, range $=4-34$ ), all of whom underwent complete resections. Symptom control was 88-100\% and 3- and 5-year OS rates were encouraging (48). Early data indicating that cytoreductive surgery of liver metastases by at least $90 \%$ could improve hormonal symptoms were reported by McEntee et al. in 1990 (49). Their results were confirmed by Sarmiento et al. in 2003 (50) in their study of 170 patients with liver metastases from si-NENs, pancreatic NENs, and NENs of unknown primary site. Among the patients with functional tumors, $96 \%$ had symptom control, and the median time to recurrence of metastasis was 45.5 months; 5- and 10-year OS were $61 \%$ and $35 \%$, respectively, and median OS was 81 months, whereas among historical controls with no surgical intervention, the median OS was 24-48 months. Thus, surgical intervention significantly improved OS and is an acceptable approach (47).

A more recent study in 2010 by Glazer et al. showed $24 \%$ morbidity and no mortality. A total of 182 patients with si-NEN or pancreatic NENs with hepatic metastases were included; 140 underwent surgical resection and several RFA. Overall, $47 \%$ presented with disease recurrence and 5- and 10 -year OS was $77 \%$ and $50 \%$, respectively. Median OS was 9.6 years. Interestingly, positive (R1 and $\mathrm{R} 2$ ) resection margins were not associated with inferior OS (51).

Mayo et al. published the results of a multicenter study including 339 patients (52). All patients had metastatic liver disease from pancreatic NENs $(40 \%)$ and si-NENs $(25 \%)$ : $70 \%$ underwent hepatectomy, 3\% RFA, and $19 \%$ both there was no prespecified percentage of cytoreductive surgery. Overall $94 \%$ of the patients had disease recurrence at 5 years, 5- and 10-year OS was $74 \%$ and $51 \%$, respectively, whereas median survival was 125 months. In the multivariate analysis, synchronous liver metastasis, non-functional tumors and extrahepatic disease were significantly associated with poor prognosis. The median OS for patients with extrahepatic disease was 85 months, whereas for those with non-functional tumors and $\mathrm{R} 2$ resection it was more than 84 months (52).

In a study by Graff-Baker et al. including 52 patients with si-NEN, a cut-off of $70 \%$ cytoreductive surgery was applied for eligibility. Positive resection margin and resection of extrahepatic disease were permitted. The median time to progression of liver metastases was 71.6 months. In the multivariate analysis, only age was significantly associated with time to progression. Disease-specific 5-year survival was $90 \%$, while all deaths were attributed to liver failure (53).

Overall, the reported morbidity of hepatectomy in these patients was 16-24\%. Most common complications include bleeding, biliary leakage, intra-abdominal abscesses and pleural effusion (50).

Intrahepatic localization of metastases may be classified into three distinct patterns (54): i. Type I: One metastasis irrespective of size (20-25\%); R0 resection confers the best survival rates (41). ii. Type II: One metastasis with accompanying small lesions in both sides of the liver (10$15 \%)$; surgical approach is debatable and multiple operations may be needed $(16,40,55)$. iii. Type III: Bilateral metastases irrespective of number or size. Surgery is only rarely indicated (16).

Eligibility for surgical intervention should be assessed according to the following criteria $(10,54)$ : iv. Grade $1 / 2$ tumors. v. Grade 3 tumors should not be treated by upfront surgery due to high risk of recurrence. vi. Negative preoperative assessment of non-operable extrahepatic disease ( ${ }^{68}$ gallium PET/CT). vii. Type I or II, as described above. viii. $\mathrm{R} 0$ resection, or $\mathrm{R} 1 / \mathrm{R} 2$ in terms of cytoreductive surgery. ix. Negative assessment for advanced carcinoid cardiac disease. $x$. Specialized surgical center.

In those with metastatic si-NENs, R0/R1 resection of the primary tumor, as well as resection of metastatic lymph nodes and distant metastases seem to provide both survival and quality of life benefit. 5- and 10- year OS rates were 46$86 \%$ and $35-79 \%$, respectively (51).

Systematic reviews have not documented a clear survival benefit in patients treated with surgery compared with those treated with other therapeutic modalities (56). This is mainly due to the lack of randomized controlled trials in the field and the selection bias that is inherent in many of the published studies. However, R0/R1/R2 surgical intervention for liver metastases from grade $1 / 2$ si-NENs remains the sole option with curative intent (40).

Neither neoadjuvant nor adjuvant chemotherapy improve outcomes in metastatic liver disease (57). There are small series indicating that immunotherapy or PRRT, or both, may improve the possibility of achieving R0 resection (58). 


\section{Locoregional Treatment}

In view of the lack of large randomized trials, the locoregional treatment approach should be on an individualized basis according to tumor and patient characteristics. Locoregional modalities should be introduced early in the treatment algorithm, but after SSA treatment for functional tumors due to the risk of carcinoid crisis (59).

RFA and other modalities of locoregional destruction. Currently available thermal destruction techniques include RFA, MWA, laser-induced thermotherapy, cryotherapy and irreversible electroporation (60).

RFA may be used either as monotherapy or in combination with hepatectomy. It is very efficient in symptom control and locoregional metastatic control. It may be performed intradermal under US or CT guidance or laparoscopically; thus it may be applied in patients ineligible for hepatectomy (13).

However, there are several limitations in RFA use (61). Only a limited number of lesions $(<5)$, of limited size (maximum diameter $<5 \mathrm{~cm}$ ) may be destroyed. Furthermore, these lesions should not be close to vital structures such as hepatic veins and porta hepatis. Although RFA may be repeated in a single metastasis, size $>5 \mathrm{~cm}$ renders RFA inapplicable (42). In patients ineligible for surgical excision, open or laparoscopic RFA may be performed by an interventional radiologist in order to detect any multifocal disease. Morbidity in these cases is acceptable (4-5\%), including bleeding, infections, and liver abscess.

The great value of this method is that it enables the treatment of liver metastases, in combination with surgery, that otherwise would be inoperable. RFA may be performed supplementary to surgery in order to destroy multifocal disease or limit the extent of a hepatectomy and, thus, the postoperative risk of liver failure (52).

RFA results in substantial symptom control in $70-80 \%$ of patients (48). Improvement in biomarkers such as $24 \mathrm{~h}$ urine 5-HIAA and serum chromogranin A occurs in $65-75 \%$ of the patients (62). Among patients treated with RFA exclusively, median OS from the time of first RFA was 3.9 years and 5year OS was $53 \%$, whereas $22 \%$ had local recurrence at 30 months (63). Most centers around the world recommend RFA because of its efficacy in tumor control and its widespread availability (64).

More recently, the introduction of MWA (65) has enabled better thermal destruction for lesions of around $5 \mathrm{~cm}$ in diameter, and it may result in more durable results compared to RFA (66). Furthermore, the introduction of irreversible electroporation even enables targeted thermal destruction close to vital structures, without sacrificing them (60). Laser-induced thermotherapy is another approach that may be applicable to lesions near vital structures, but the available data are rather immature (67). Cryotherapy is not currently recommended due to the scarcity of data (68); a study including 13 patients with gastrointestinal NENs indicated that 12 patients had complete tumor destruction, two had recurrent tumors and 12 were alive at 12 months of follow-up (69).

Intra-arterial liver treatment (TACE, TAE, SIRT). Intraarterial modalities, including TAE, TACE and SIRT (drugeluting bead TACE) are indicated in patients ineligible for surgery and can be performed repeatedly. Their rationale is that liver metastases from si-NENs usually have rich vasculature originating from the hepatic artery (70).

TAE and TACE may result in reduction of tumor size and symptom control in more than $50 \%$ (53-100\%) of patients for $10-55$ months and radiological response in $35-74 \%$ for $6-$ 63 months (71). To date, there are no data indicating TACE superiority compared to RFA (42). The most widely used chemotherapeutic drugs in TACE are doxorubicin and streptozotocin (71).

TACE should be conducted at centers with expertise due to the associated morbidity. Mortality ranges between 0 and $5.6 \%$ (0-3.3\% at specialized centers) whereas morbidity ranges between 28 and $90 \%$ (66). There is also a relative contradiction in portal vein thrombosis and liver failure. Other relative contradictions include Whipple procedure and hepatopulmonary shunts. Among the major complications are necrosis of choledochal cyst (hence prophylactic cholecystectomy is recommended), hepatorenal syndrome, pancreatitis, liver abscess and hepatic artery aneurysm (70).

SIRT (drug-eluting bead TACE) with ${ }^{90}$ Y-tetraazacyclododecane tetra-acetic acid lanreotide (with or without embolism) is effective in patients with large hepatic metastases with SRS positivity according to a multicenter study (72): $22.7 \%$ of the patients had stable disease, $60 \%$ partial response, $27 \%$ complete response and $4.9 \%$ had progressive disease. Long-term outcomes following SIRT resulted in response in $62.7 \%$, disease stabilization in $32.5 \%$, and 1-, 2- and 3-year OS at $72.5 \%$, $62.5 \%$ and $45 \%$, respectively (40).

An international multicenter trial showed that safety and response rates were similar for SIRT and TACE at 6 months (73), whereas at 12 months, the SIRT-treated group had significantly lower response rates compared to the TACEtreated group (46\% vs. 66\%). Toxicities include fatigue and nausea $(<10 \%)$, as well as pulmonary shunts, gastritis, duodenal ulcer, and liver fibrosis. SIRT-mediated liver radiotherapy may result in liver lobe atrophy and contralateral hypertrophy. Thus it may be used for partial volume effect and down-staging (74). Although promising, more data are needed in order to determine the role of SIRT in therapeutics of gastrointestinal NENs (16). 
Liver transplantation. Liver transplantation is an alternative option for patients with unresectable metastases (75). Only $0.2-0.3 \%$ of all liver transplantations are conducted due to metastatic liver disease from NENs according to the United Network for Organ Sharing database and the European Liver Transplant Registry (76, 77). Patients should be selected on a rigorous basis (77). Eligibility criteria according to Mazzaferro et al. (78) include: i. Previous R0 resection of primary tumor. ii. Histological diagnosis of well-differentiated si-NEN (grade 1/2, Ki-67<10\%). iii. Portal vein should be the venous drainage of the primary tumor. iv. Absence or complete resection of extrahepatic lesions. v. Liver metastatic disease in $<50 \%$ of total liver volume. vi. Stable disease under treatment for at least 6 months before transplantation. vii. Age $<55$ years (relative contraindication).

European Neuroendocrine Tumor Society Criteria are similar to those of Pavel et al. (70) and include: i. Transplantation mortality $<10 \%$. ii. Absence of extrahepatic disease by PET/CT. iii. Previous resection of primary tumor. iv. Grade 1/2 NET. v. Age $<50$ years. vi. Low Ki-67. Explorative laparotomy or laparoscopy may be necessary for detecting peritoneal disease before transplantation. Failure of primary tumor detection should not be considered as absolute contraindication (79).

Patients with small cell tumors, grade 3 NETs or neuroendocrine carcinomas, with major comorbidities, NETs that do not drain into portal vein, extrahepatic metastases (excluding perihilar lymph nodes) and carcinoid cardiac disease (40) should be excluded. Only when the eligibility criteria are metastatic is the patient undergoing liver transplantation expected to have better OS benefit compared to those treated with conservative methods (79). However, these criteria are currently under validation and they are subject to change in the light of new data from future prospective studies (40).

Liver transplantation for NETs is associated with a 5-year OS comparable or better than hepatocellular carcinoma (76) and ranges between $36-90 \%$, with disease-free survival at $30-$ $77 \%$ (40), whereas in multicenter studies, the 5-year OS was $47-49 \%(76,80)$, but significantly lower $(12 \%)$ in the subgroup with adverse prognostic features such as invasion of large vessels and greater extent of extrahepatic disease (80). In another study that applied strict eligibility criteria (78), 5and 10 -year OS were $97.2 \%$ and $50.9 \%$, respectively, whereas other treatment modalities resulted in rates of $88.8 \%$ and $22.4 \%$, respectively $(p<0.001)$. The survival benefit from transplantation was 6.82 months at 5 years $(p=0.019)$ and 38.49 months at 10 years $(p<0.001)(78)$.

In conclusion, orthotopic or living donor liver transplantation is a viable option only when eligibility criteria are strictly addressed at specialized centers with a multidisciplinary treatment approach (40).

\section{Diffuse Peritoneal Carcinomatosis (PC)}

Approximately $17 \%$ (5-33\%) of patients with si-NENs have miliary spread in the peritoneal cavity. Peritoneal cavity is the third most common site of metastasis following lymph nodes and liver (81). The reported incidence of PC is approximately $13.6 \%$. Signs and symptoms of bowel obstruction or ascites may indicate PC. Several patients present with 'frozen abdomen', especially in the pelvis, despite the absence of extensive liver metastatic disease (32). The presence of bulky disease in the peritoneal cavity is an ominous prognostic characteristic (81).

Surgical intervention in PC due to NETs remains debatable $(81,82)$. However, it may be necessary for preventing serious complications such as bowel obstruction, mesenteric fibrosis, gastrointestinal bleeding, and portal vein hypertension (55). Following a surgical intervention, the preferred reporting system is the completeness of cytoreduction (CCR) that reflects the residual disease (83). CCR is assessed as follows (84): CCR-0: No macroscopically evident residual lesions. CCR-1: Microscopically evident residual lesions $<2.5 \mathrm{~mm}$. CCR-2: Residual lesions between $2.5 \mathrm{~mm}$ and $2.5 \mathrm{~cm}$. CCR-3: Residual lesions $>2.5 \mathrm{~cm}$. CCR is the main prognostic factor for OS after surgery and is independent of the initial exten of PC (83). Thus, surgery should be opted for patients with anticipated low CCR score after the operation including, those with peritoneal carcinomatosis index $<20$, or abdominal gravity peritoneal carcinomatosis score (GPS)-A or GPS-B low (81).

Hyperthermic intraperitoneal chemotherapy (HIPEC) may improve survival rates by eradicating small PC lesions. HIPEC is applied after an extended surgical intervention including macroscopic disease, excision of the peritoneum, omentum, ovaries, uterine etc. The main limitation of HIPEC in this setting is that chemotherapy is used against tumors with a low proliferative rate (85). Added risk of morbidity and mortality should be also taken into consideration when HIPEC is considered simultaneously with another major surgery (81).

\section{Asymptomatic Primary Tumor}

Due to their small size and the submucosal site, si-NENs are rarely diagnosed before symptoms occur. In this case, an aggressive approach is recommended, especially in those with a family history of si-NENs (86). Lack of symptomatic disease is by no means a contradiction for surgery (30). Early surgical intervention may prevent an emergency surgery that would be accompanied by high morbidity and mortality risk $(9,30)$. More than $80 \%$ of these patients have multifocal disease and one-third of them have stage III disease. Almost one half of those with si-NENs under $10 \mathrm{~mm}$ have lymph node metastases (35). In this context, si-NENs should be treated aggressively 
with surgical excision and lymphadenectomy (10). Among patients with asymptomatic si-NENs with distant metastases, a recent study demonstrated no survival benefit among those that underwent prophylactic locoregional surgery compared to those that underwent delayed surgery or no surgery according to clinical indications. Randomized clinical trials are needed in order to elucidate this field (6).

Resection of primary asymptomatic tumor in the synchronous presence of unresectable liver metastases is debatable. The rationale of this approach is that resecting the primary tumor eliminates the burden and the potential complications that may arise and could prove fatal in the future. Unfortunately, there has been no randomized study, although unresectable hepatic metastases range between 15$80 \%$ of gastrointestinal NEN cases (40). In a meta-analysis, Capurso et al. showed that such an approach confers OS benefit, with OS reaching 75-139 months versus 50-88 months for a conservative approach (87). Prospective studies should be conducted in order to provide more rigorous data in this field.

\section{Conclusion}

As in all gastroenteropancreatic NENs, si-NEN incidence is rising steadily. Disease symptoms depend on stage and anatomical site. Carcinoid syndrome is more frequent among patients with advanced liver metastases. Treatment of logoregional disease should include surgery, while a surgical approach is also applicable to distant metastases and confers a survival benefit. Lifelong follow-up is of high importance, especially for young patients. There is a intense scientific interest in this field and the management of patients with siNENs is surely going to be further improved in the oncoming years.

\section{References}

1 Maggard MA, O'Connell JB and Ko CY: Updated populationbased review of carcinoid tumors. Ann Surg 240(1): 117-122, 2004.

2 Kim JY and Hong SM: Recent updates on neuroendocrine tumors from the gastrointestinal and pancreatobiliary tracts. Arch Pathol Lab Med 140(5): 437-448, 2016.

3 Yao JC, Hassan M, Phan A, Dagohoy C, Leary C, Mares JE, Abdalla EK, Fleming JB, Vauthey JN, Rashid A and Evans DB: One hundred years after "carcinoid": Epidemiology of and prognostic factors for neuroendocrine tumors in 35,825 cases in the United States. J Clin Oncol 26(18): 3063-3072, 2008.

4 Modlin IM, Kidd M, Latich I, Zikusoka MN and Shapiro MD: Current status of gastrointestinal carcinoids. Gastroenterology 128(6): 1717-1751, 2005.

5 Haugvik SP, Basim Ibrahim I, Hedenstrom P, Valente R, Hayes AJ, Siuka D, Gladhaug IP and Capurso G: Smoking, alcohol and family history of cancer as risk factors for small intestinal neuroendocrine tumors: A systematic review and meta-analysis. Scand J Gastroenterol 52(8): 797-802, 2017.
6 Norlen O, Stalberg P, Oberg K, Eriksson J, Hedberg J, Hessman O, Janson ET, Hellman P and Akerstrom G: Long-term results of surgery for small intestinal neuroendocrine tumors at a tertiary referral center. World J Surg 36(6): 1419-1431, 2012.

7 Berge $\mathrm{T}$ and Linell F: Carcinoid tumours. Frequency in a defined population during a 12-year period. Acta Pathol Microbiol Scand A 84(4): 322-330, 1976.

8 Schnirer, II, Yao JC and Ajani JA: Carcinoid--a comprehensive review. Acta Oncol 42(7): 672-692, 2003.

9 Woltering EA, Voros BA, Beyer DT, Wang YZ, Thiagarajan R, Ryan P, Wright A, Ramirez RA, Ricks MJ and Boudreaux JP: Aggressive surgical approach to the management of neuroendocrine tumors: A report of 1,000 surgical cytoreductions by a single institution. J Am Coll Surg 224(4): 434-447, 2017.

10 Partelli S, Bartsch DK, Capdevila J, Chen J, Knigge U, Niederle B, Nieveen van Dijkum EJ, Pape UF, Pascher A, Ramage J, Reed N, Ruszniewski P, Scoazec JY, Toumpanakis C, Kianmanesh R, Falconi $\mathrm{M}$ and all other Antibes Consensus Conference participants: ENETs consensus guidelines for standard of care in neuroendocrine tumours: Surgery for small intestinal and pancreatic neuroendocrine tumours. Neuroendocrinology 105(3): 255-265, 2017.

11 Farley HA and Pommier RF: Surgical treatment of small bowel neuroendocrine tumors. Hematol Oncol Clin North Am 30(1): 49-61, 2016.

12 Modlin IM, Oberg K, Chung DC, Jensen RT, de Herder WW, Thakker RV, Caplin M, Delle Fave G, Kaltsas GA, Krenning EP, Moss SF, Nilsson O, Rindi G, Salazar R, Ruszniewski P and Sundin A: Gastroenteropancreatic neuroendocrine tumours. Lancet Oncol 9(1): 61-72, 2008.

13 Farra CJ and Rodgers ES: Small bowel neuroendocrine tumors. In: Surgical Endocrinopathies: Clinical Management and the Founding Figures. Pasieka LJ and Lee AJ (eds.). Springer International Publishing: Cham, pp. 323-331, 2015.

14 Boudreaux JP, Klimstra DS, Hassan MM, Woltering EA, Jensen RT, Goldsmith SJ, Nutting C, Bushnell DL, Caplin ME, Yao JC and North American Neuroendocrine Tumor S: The NANETs consensus guideline for the diagnosis and management of neuroendocrine tumors: Well-differentiated neuroendocrine tumors of the jejunum, ileum, appendix, and cecum. Pancreas 39(6): 753-766, 2010

15 Parris WC, Oates JA, Kambam J, Shmerling R and Sawyers JF: Pre-treatment with somatostatin in the anaesthetic management of a patient with carcinoid syndrome. Can J Anaesth 35(4): 413416, 1988.

16 Pavel M, O'Toole D, Costa F, Capdevila J, Gross D, Kianmanesh R, Krenning E, Knigge U, Salazar R, Pape UF, Oberg K and Vienna Consensus Conference participants: ENETs consensus guidelines update for the management of distant metastatic disease of intestinal, pancreatic, bronchial neuroendocrine neoplasms (NEN) and NEN of unknown primary site. Neuroendocrinology 103(2): 172-185, 2016.

17 Figueiredo MN, Maggiori L, Gaujoux S, Couvelard A, Guedj N, Ruszniewski $P$ and Panis Y: Surgery for small-bowel neuroendocrine tumors: Is there any benefit of the laparoscopic approach? Surg Endosc 28(5): 1720-1726, 2014.

18 Pasquer A, Walter T, Hervieu V, Forestier J, Scoazec JY, Lombard-Bohas C and Poncet G: Surgical management of small bowel neuroendocrine tumors: Specific requirements and their impact on staging and prognosis. Ann Surg Oncol 22 Suppl 3(3): S742-749, 2015. 
19 Watzka FM, Fottner C, Miederer M, Weber MM, Schad A, Lang $\mathrm{H}$ and Musholt TJ: Surgical treatment of nen of small bowel: A retrospective analysis. World J Surg 40(3): 749-758, 2016.

20 Landry CS, Lin HY, Phan A, Charnsangavej C, Abdalla EK, Aloia T, Nicolas Vauthey J, Katz MH, Yao JC and Fleming JB: Resection of at-risk mesenteric lymph nodes is associated with improved survival in patients with small bowel neuroendocrine tumors. World J Surg 37(7): 1695-1700, 2013.

21 Akerstrom G and Hellman P: Surgical aspects of neuroendocrine tumours. Eur J Cancer 45(Suppl 1): 237-250, 2009.

22 Le Roux C, Lombard-Bohas C, Delmas C, Dominguez-Tinajero S, Ruszniewski P, Samalin E, Raoul JL, Renard P, Baudin E, Robaskiewicz M, Mitry E, Cadiot G and Groupe d'etude des Tumeurs E: Relapse factors for ileal neuroendocrine tumours after curative surgery: A retrospective french multicentre study. Dig Liver Dis 43(10): 828-833, 2011.

23 James D. Brierley MKG, Christian Wittekind (Herausgeber): Tnm classification of malignant tumours (ebook). WileyBlackwell (Verlag): 8. Auflage 272 Seiten, 2016.

24 Almond LM, Hodson J, Ford SJ, Gourevitch D, Roberts KJ, Shah T, Isaac J and Desai A: Role of palliative resection of the primary tumour in advanced pancreatic and small intestinal neuroendocrine tumours: A systematic review and meta-analysis. Eur J Surg Oncol 43(10): 1808-1815, 2017.

25 Strosberg JR, Weber JM, Feldman M, Coppola D, Meredith K and Kvols LK: Prognostic validity of the american joint committee on cancer staging classification for midgut neuroendocrine tumors. J Clin Oncol 31(4): 420-425, 2013.

26 Pasquer A, Walter T, Rousset P, Hervieu V, Forestier J, LombardBohas $\mathrm{C}$ and Poncet $\mathrm{G}$ : Lymphadenectomy during small bowel neuroendocrine tumor surgery: The concept of skip metastases. Ann Surg Oncol 23(Suppl 5): 804-808, 2016.

27 Wang YZ, Diebold A, Woltering E, King H, Boudreaux JP, Anthony LB and Campeau R: Radioguided exploration facilitates surgical cytoreduction of neuroendocrine tumors. J Gastrointest Surg 16(3): 635-640, 2012.

28 Lardiere-Deguelte S, de Mestier L, Appere F, Vullierme MP, Zappa M, Hoeffel C, Noaves M, Brixi H, Hentic O, Ruszniewski P, Cadiot G, Panis Y and Kianmanesh R: Toward a preoperative classification of lymph node metastases in patients with small intestinal neuroendocrine tumors in the era of intestinal-sparing surgery. Neuroendocrinology 103(5): 552-559, 2016.

29 Pasquer A and Poncet G: Small bowel neuroendocrine tumors surgery: Technical point - with video. J Visc Surg 154(1): 61-62, 2017.

30 Boudreaux JP: Surgery for gastroenteropancreatic neuroendocrine tumors (gepnets). Endocrinol Metab Clin North Am 40(1): 163-171, ix, 2011.

31 Wang YZ, Chauhan A, Rau J, Diebold AE, Opoku-Boateng A, Ramcharan T, Boudreaux JP and Woltering EA: Neuroendocrine tumors (nets) of unknown primary: Is early surgical exploration and aggressive debulking justifiable? Chin Clin Oncol 5(1): 4, 2016.

32 Modlin IM, Shapiro MD and Kidd M: Carcinoid tumors and fibrosis: An association with no explanation. Am J Gastroenterol 99(12): 2466-2478, 2004.

33 Daskalakis K, Karakatsanis A, Stalberg P, Norlen O and Hellman $\mathrm{P}$ : Clinical signs of fibrosis in small intestinal neuroendocrine tumours. Br J Surg 104(1): 69-75, 2017.

34 Boudreaux JP, Putty B, Frey DJ, Woltering E, Anthony L, Daly I, Ramcharan T, Lopera J and Castaneda W: Surgical treatment of advanced-stage carcinoid tumors: Lessons learned. Ann Surg 241(6): 839-845; discussion 845-836, 2005.

35 Walsh JC, Schaeffer DF, Kirsch R, Pollett A, Manzoni M, Riddell RH and Albarello L: Ileal "carcinoid" tumors-small size belies deadly intent: High rate of nodal metastasis in tumors $<=1 \mathrm{~cm}$ in size. Hum Pathol 56: 123-127, 2016.

36 Chambers AJ, Pasieka JL, Dixon E and Rorstad O: The palliative benefit of aggressive surgical intervention for both hepatic and mesenteric metastases from neuroendocrine tumors. Surgery 144(4): 645-651; discussion 651-643, 2008.

37 Ethun CG, Postlewait LM, Baptiste GG, McInnis MR, Cardona K, Russell MC, Kooby DA, Staley CA and Maithel SK: Small bowel neuroendocrine tumors: A critical analysis of diagnostic work-up and operative approach. J Surg Oncol 114(6): 671-676, 2016.

38 Niederle MB, Hackl M, Kaserer $\mathrm{K}$ and Niederle B: Gastroenteropancreatic neuroendocrine tumours: The current incidence and staging based on the WHO and European Neuroendocrine Tumour Society classification: An analysis based on prospectively collected parameters. Endocr Relat Cancer 17(4): 909-918, 2010.

39 Lawrence B, Gustafsson BI, Chan A, Svejda B, Kidd M and Modlin IM: The epidemiology of gastroenteropancreatic neuroendocrine tumors. Endocrinol Metab Clin North Am 40(1): 1-18, vii, 2011.

40 Frilling A, Modlin IM, Kidd M, Russell C, Breitenstein S, Salem R, Kwekkeboom D, Lau WY, Klersy C, Vilgrain V, Davidson B, Siegler M, Caplin M, Solcia E, Schilsky R and Working Group on Neuroendocrine Liver M: Recommendations for management of patients with neuroendocrine liver metastases. Lancet Oncol 15(1): e8-21, 2014.

41 Partelli S, Inama M, Rinke A, Begum N, Valente R, Fendrich V, Tamburrino D, Keck T, Caplin ME, Bartsch D, Thirlwell C, Fusai $\mathrm{G}$ and Falconi M: Long-term outcomes of surgical management of pancreatic neuroendocrine tumors with synchronous liver metastases. Neuroendocrinology 102(1-2): 6876, 2015.

42 Steinmuller T, Kianmanesh R, Falconi M, Scarpa A, Taal B, Kwekkeboom DJ, Lopes JM, Perren A, Nikou G, Yao J, Delle Fave GF, O'Toole D and Frascati Consensus Conference participants: Consensus guidelines for the management of patients with liver metastases from digestive (neuro)endocrine tumors: Foregut, midgut, hindgut, and unknown primary. Neuroendocrinology 87(1): 47-62, 2008.

43 Dasari A, Shen C, Halperin D, Zhao B, Zhou S, Xu Y, Shih T and Yao JC: Trends in the incidence, prevalence, and survival outcomes in patients with neuroendocrine tumors in the united states. JAMA Oncol 3(10): 1335-1342, 2017.

44 Cavalcoli F, Rausa E, Conte D, Nicolini AF and Massironi S: Is there still a role for the hepatic locoregional treatment of metastatic neuroendocrine tumors in the era of systemic targeted therapies? World J Gastroenterol 23(15): 2640-2650, 2017.

45 Moris D, Dimitroulis D, Vernadakis S, Papalampros A, Spartalis E, Petrou A, Pawlik TM and Felekouras E: Parenchymal-sparing hepatectomy as the new doctrine in the treatment of livermetastatic colorectal disease: Beyond oncological outcomes. Anticancer Res 37(1): 9-14, 2017.

46 Maxwell JE, Sherman SK, O’Dorisio TM, Bellizzi AM and Howe JR: Liver-directed surgery of neuroendocrine metastases: What is the optimal strategy? Surgery 159(1): 320-333, 2016. 
47 Farley HA and Pommier RF: Treatment of neuroendocrine liver metastases. Surg Oncol Clin N Am 25(1): 217-225, 2016.

48 Chamberlain RS, Canes D, Brown KT, Saltz L, Jarnagin W, Fong Y and Blumgart LH: Hepatic neuroendocrine metastases: Does intervention alter outcomes? J Am Coll Surg 190(4): 432445, 2000.

49 McEntee GP, Nagorney DM, Kvols LK, Moertel CG and Grant CS: Cytoreductive hepatic surgery for neuroendocrine tumors. Surgery 108(6): 1091-1096, 1990.

50 Sarmiento JM, Heywood G, Rubin J, Ilstrup DM, Nagorney DM and Que FG: Surgical treatment of neuroendocrine metastases to the liver: A plea for resection to increase survival. J Am Coll Surg 197(1): 29-37, 2003.

51 Glazer ES, Tseng JF, Al-Refaie W, Solorzano CC, Liu P, Willborn KA, Abdalla EK, Vauthey JN and Curley SA: Longterm survival after surgical management of neuroendocrine hepatic metastases. HPB (Oxford) 12(6): 427-433, 2010.

52 Mayo SC, de Jong MC, Pulitano C, Clary BM, Reddy SK, Gamblin TC, Celinksi SA, Kooby DA, Staley CA, Stokes JB, Chu CK, Ferrero A, Schulick RD, Choti MA, Mentha G, Strub J, Bauer TW, Adams RB, Aldrighetti L, Capussotti L and Pawlik TM: Surgical management of hepatic neuroendocrine tumor metastasis: Results from an international multiinstitutional analysis. Ann Surg Oncol 17(12): 3129-3136, 2010.

53 Graff-Baker AN, Sauer DA, Pommier SJ and Pommier RF: Expanded criteria for carcinoid liver debulking: Maintaining survival and increasing the number of eligible patients. Surgery 156(6): 1369-1376; discussion 1376-1367, 2014.

54 Frilling A, Li J, Malamutmann E, Schmid KW, Bockisch A and Broelsch CE: Treatment of liver metastases from neuroendocrine tumours in relation to the extent of hepatic disease. Br J Surg 96(2): 175-184, 2009.

55 Kianmanesh R, Sauvanet A, Hentic O, Couvelard A, Levy P, Vilgrain V, Ruszniewski $\mathrm{P}$ and Belghiti J: Two-step surgery for synchronous bilobar liver metastases from digestive endocrine tumors: A safe approach for radical resection. Ann Surg 247(4): 659-665, 2008.

56 Gurusamy KS, Pamecha V, Sharma D and Davidson BR: Palliative cytoreductive surgery versus other palliative treatments in patients with unresectable liver metastases from gastro-entero-pancreatic neuroendocrine tumours. Cochrane Database Syst Rev 1: CD007118, 2009.

57 Maire F, Hammel P, Kianmanesh R, Hentic O, Couvelard A, Rebours V, Zappa M, Raymond E, Sauvanet A, Louvet C, Levy $\mathrm{P}$, Belghiti $\mathrm{J}$ and Ruszniewski P: Is adjuvant therapy with streptozotocin and 5-fluorouracil useful after resection of liver metastases from digestive endocrine tumors? Surgery 145(1): 69-75, 2009

58 Sowa-Staszczak A, Pach D, Chrzan R, Trofimiuk M, Stefanska A, Tomaszuk M, Kolodziej M, Mikolajczak R, Pawlak D and Hubalewska-Dydejczyk A: Peptide receptor radionuclide therapy as a potential tool for neoadjuvant therapy in patients with inoperable neuroendocrine tumours (NETs). Eur J Nucl Med Mol Imaging 38(9): 1669-1674, 2011.

59 de Baere T, Deschamps F, Tselikas L, Ducreux M, Planchard D, Pearson E, Berdelou A, Leboulleux S, Elias D and Baudin E: Gep-nets update: Interventional radiology: Role in the treatment of liver metastases from GEP-NETs. Eur J Endocrinol 172(4): R151-166, 2015.
60 Kourounis G, Paul Tabet P, Moris D, Papalambros A, Felekouras E, Georgiades F, Astras G and Petrou A: Irreversible electroporation (nanoknife(r) treatment) in the field of hepatobiliary surgery: Current status and future perspectives. J BUON 22(1): 141-149, 2017.

61 Geranios A, Pikoulis E, Papalois A, Kontos M, Agrogiannis G, Petrou A, Pavlakis E and Felekouras E: Radiofrequency ablation of the pancreas: Protective effect of local cooling techniques. Am Surg 81(5): 483-491, 2015.

62 Eriksson J, Stalberg P, Nilsson A, Krause J, Lundberg C, Skogseid B, Granberg D, Eriksson B, Akerstrom G and Hellman $\mathrm{P}$ : Surgery and radiofrequency ablation for treatment of liver metastases from midgut and foregut carcinoids and endocrine pancreatic tumors. World J Surg 32(5): 930-938, 2008.

63 Mazzaglia PJ, Berber E, Milas $M$ and Siperstein AE: Laparoscopic radiofrequency ablation of neuroendocrine liver metastases: A 10-year experience evaluating predictors of survival. Surgery 142(1): 10-19, 2007.

64 Vogl TJ, Straub R, Eichler K, Sollner O and Mack MG: Colorectal carcinoma metastases in liver: Laser-induced interstitial thermotherapy - local tumor control rate and survival data. Radiology 230(2): 450-458, 2004.

65 Niessen C, Beyer LP, Pregler B, Dollinger M, Trabold B, Schlitt HJ, Jung EM, Stroszczynski C and Wiggermann P: Percutaneous ablation of hepatic tumors using irreversible electroporation: A prospective safety and midterm efficacy study in 34 patients. J Vasc Interv Radiol 27(4): 480-486, 2016.

66 Vogl TJ, Naguib NN, Zangos S, Eichler K, Hedayati A and Nour-Eldin NE: Liver metastases of neuroendocrine carcinomas: Interventional treatment via transarterial embolization, chemoembolization and thermal ablation. Eur J Radiol 72(3): 517-528, 2009.

67 Vogl TJ, Freier V, Nour-Eldin NE, Eichler K, Zangos S and Naguib NN: Magnetic resonance-guided laser-induced interstitial thermotherapy of breast cancer liver metastases and other noncolorectal cancer liver metastases: An analysis of prognostic factors for long-term survival and progression-free survival. Invest Radiol 48(6): 406-412, 2013.

68 Bala MM, Riemsma RP, Wolff R and Kleijnen J: Cryotherapy for liver metastases. Cochrane Database Syst Rev 6: CD009058, 2013.

69 Seifert JK, Cozzi PJ and Morris DL: Cryotherapy for neuroendocrine liver metastases. Semin Surg Oncol 14(2): 175$183,1998$.

70 Pavel M, Baudin E, Couvelard A, Krenning E, Oberg K, Steinmuller T, Anlauf M, Wiedenmann B, Salazar R and Barcelona Consensus Conference participants: ENETs consensus guidelines for the management of patients with liver and other distant metastases from neuroendocrine neoplasms of foregut, midgut, hindgut, and unknown primary. Neuroendocrinology 95(2): 157-176, 2012.

71 Chen JX, Rose S, White SB, El-Haddad G, Fidelman N, Yarmohammadi H, Hwang W, Sze DY, Kothary N, Stashek K, Wileyto EP, Salem R, Metz DC and Soulen MC: Embolotherapy for neuroendocrine tumor liver metastases: Prognostic factors for hepatic progression-free survival and overall survival. Cardiovasc Intervent Radiol 40(1): 69-80, 2017.

72 McStay MK, Maudgil D, Williams M, Tibballs JM, Watkinson AF, Caplin ME and Buscombe JR: Large-volume liver metastases from neuroendocrine tumors: Hepatic intraarterial ${ }^{90}$ Y-DOTA-lanreotide as effective palliative therapy. Radiology 237(2): 718-726, 2005. 
73 Whitney R, Valek V, Fages JF, Garcia A, Narayanan G, Tatum C, Hahl $M$ and Martin RC 2nd: Transarterial chemoembolization and selective internal radiation for the treatment of patients with metastatic neuroendocrine tumors: A comparison of efficacy and cost. Oncologist 16(5): 594-601, 2011.

74 Cucchetti A, Cappelli A, Ercolani G, Mosconi C, Cescon M, Golfieri R and Pinna AD: Selective internal radiation therapy (SIRT) as conversion therapy for unresectable primary liver malignancies. Liver Cancer 5(4): 303-311, 2016.

75 Moris D, Tsilimigras DI, Chakedis J, Beal EW, Felekouras E, Vernadakis S, Schizas D, Fung JJ and Pawlik TM: Liver transplantation for unresectable colorectal liver metastases: A systematic review. J Surg Oncol 116(3): 288-297, 2017.

76 Gedaly R, Daily MF, Davenport D, McHugh PP, Koch A, Angulo $\mathrm{P}$ and Hundley JC: Liver transplantation for the treatment of liver metastases from neuroendocrine tumors: An analysis of the UNOS database. Arch Surg 146(8): 953-958, 2011.

77 Moris D, Tsilimigras DI, Ntanasis-Stathopoulos I, Beal EW, Felekouras E, Vernadakis S, Fung JJ and Pawlik TM: Liver transplantation in patients with liver metastases from neuroendocrine tumors: A systematic review. Surgery 162(3): 525-536, 2017.

78 Mazzaferro V, Sposito C, Coppa J, Miceli R, Bhoori S, Bongini M, Camerini T, Milione M, Regalia E, Spreafico C, Gangeri L, Buzzoni R, de Braud FG, De Feo T and Mariani L: The longterm benefit of liver transplantation for hepatic metastases from neuroendocrine tumors. Am J Transplant 16(10): 2892-2902, 2016.

79 Le Treut YP, Gregoire E, Klempnauer J, Belghiti J, Jouve E, Lerut J, Castaing D, Soubrane O, Boillot O, Mantion G, Homayounfar K, Bustamante M, Azoulay D, Wolf P, Krawczyk M, Pascher A, Suc B, Chiche L, de Urbina JO, Mejzlik V, Pascual M, Lodge JP, Gruttadauria S, Paye F, Pruvot FR, Thorban S, Foss A, Adam R and For E: Liver transplantation for neuroendocrine tumors in Europe-results and trends in patient selection: A 213-case European Liver Transplant Registry study. Ann Surg 257(5): 807-815, 2013.

80 Le Treut YP, Gregoire E, Belghiti J, Boillot O, Soubrane O, Mantion G, Cherqui D, Castaing D, Ruszniewski P, Wolf P, Paye F, Salame E, Muscari F, Pruvot FR and Baulieux J: Predictors of long-term survival after liver transplantation for metastatic endocrine tumors: An 85-case French multicentric report. Am J Transplant 8(6): 1205-1213, 2008.

81 de Mestier L, Lardiere-Deguelte S, Brixi H, O'Toole D, Ruszniewski P, Cadiot $\mathrm{G}$ and Kianmanesh R: Updating the surgical management of peritoneal carcinomatosis in patients with neuroendocrine tumors. Neuroendocrinology 101(2): 105$111,2015$.

$82 \mathrm{NCCN}$ : NCCN clinical practice guidelines in oncology. NCCN guidelines neuroendocrine tumors. Version 2.2017 - March 29, 2017. https://wwwnccnorg/professionals/physician_gls/PDF/ neuroendocrinepdf, 2017.
83 Kianmanesh R, Ruszniewski P, Rindi G, Kwekkeboom D, Pape UF, Kulke M, Sevilla Garcia I, Scoazec JY, Nilsson O, Fazio N, Lesurtel M, Chen YJ, Eriksson B, Cioppi F, O'Toole D and Palma de Mallorca Consensus Conference P: ENETs consensus guidelines for the management of peritoneal carcinomatosis from neuroendocrine tumors. Neuroendocrinology 91(4): 333-340, 2010.

84 Gilly FN, Cotte E, Brigand C, Monneuse O, Beaujard AC, Freyer $\mathrm{G}$ and Glehen O: Quantitative prognostic indices in peritoneal carcinomatosis. Eur J Surg Oncol 32(6): 597-601, 2006.

85 Elias D, David A, Sourrouille I, Honore C, Goere D, Dumont F, Stoclin A and Baudin E: Neuroendocrine carcinomas: Optimal surgery of peritoneal metastases (and associated intra-abdominal metastases). Surgery 155(1): 5-12, 2014.

86 Hughes MS, Azoury SC, Assadipour Y, Straughan DM, Trivedi AN, Lim RM, Joy G, Voellinger MT, Tang DM, Venkatesan AM, Chen CC, Louie A, Quezado MM, Forbes J and Wank SA: Prospective evaluation and treatment of familial carcinoid small intestine neuroendocrine tumors (si-NETs). Surgery 159(1): 350356, 2016.

87 Capurso G, Rinzivillo M, Bettini R, Boninsegna L, Delle Fave $\mathrm{G}$ and Falconi M: Systematic review of resection of primary midgut carcinoid tumour in patients with unresectable liver metastases. Br J Surg 99(11): 1480-1486, 2012.

88 Niederle B, Pape UF, Costa F, Gross D, Kelestimur F, Knigge U, Oberg K, Pavel M, Perren A, Toumpanakis C, O'Connor J, O'Toole D, Krenning E, Reed N, Kianmanesh R and Vienna Consensus Conference participants: ENETs consensus guidelines update for neuroendocrine neoplasms of the jejunum and ileum. Neuroendocrinology 103(2): 125-138, 2016.

89 Ohrvall U, Eriksson B, Juhlin C, Karacagil S, Rastad J, Hellman $\mathrm{P}$ and Akerstrom G: Method for dissection of mesenteric metastases in mid-gut carcinoid tumors. World J Surg 24(11): 1402-1408, 2000.

90 Jann H, Roll S, Couvelard A, Hentic O, Pavel M, MullerNordhorn J, Koch M, Rocken C, Rindi G, Ruszniewski P, Wiedenmann B and Pape UF: Neuroendocrine tumors of midgut and hindgut origin: Tumor-node-metastasis classification determines clinical outcome. Cancer 117(15): 3332-3341, 2011.

91 Hellman P, Lundstrom T, Ohrvall U, Eriksson B, Skogseid B, Oberg K, Tiensuu Janson E and Akerstrom G: Effect of surgery on the outcome of midgut carcinoid disease with lymph node and liver metastases. World J Surg 26(8): 991-997, 2002.

Received December 29, 2017

Revised January 24, 2018

Accepted January 30, 2018 